ПЫРМА Роман Васильевич - кандидат политических наук, доцент департамента политологии факультета социальных наук и массовых коммуникаций Финансового университета при Правительстве РФ (125993, Россия, г. Москва, ГСП-3, Ленинградский пр-кт, 49; pугта@таil.ru)

\title{
ФАКТОРЫ ФОРМИРОВАНИЯ УСТАНОВОК И СТРАТЕГИЙ ГРАЖДАНСКОГО АКТИВИЗМА У МОЛОДЕЖИ РОССИИ*
}

Аннотация. В статье на основе проведения глубинных интервью с лидерами и активистами общественных и политических организаций определяются факторы, влияющие на формирование ценностей гражданского активизма молодежи. Структура исследования включает рассмотрение способов вовлечения в гражданскую активность, особенностей консолидации внутри организации (ценности, убеждения, идентичности, авторитет лидера, механизмы сплочения), взаимодействия со структурами власти и гражданского общества, привлечения сторонников в офлайн- и онлайн-средах. Автор выявляет факторы формирования культуры и установок гражданской активности, соотношение личных жизненных и гражданских ценностей, определяет роль молодежи в организациях.

Ключевые слова: гражданский активизм, политическое участие, протестные настроения, конвенциональные установки, молодежь

\footnotetext{
*Статья подготовлена по результатам исследований, выполненныхза счет бюджетных средств по государственному заданию Финуниверситету.
}

Определение гражданского активизма. В российских исследованиях гражданский активизм рассматривается как сложное социальное явление, включающее различные поведенческие практики, ценности, формы и мотивы участия граждан в общественно-политической деятельности. Гражданский активизм является органичной частью жизни современного общества и представляет собой не реакцию на дисфункции и противоречия социально-политической системы, а признак и условие ее нормального функционирования и развития [Трофимова 2014]. Социальную базу гражданского активизма отдельные исследователи рассматривают на основе типологии, построенной на включенности в гражданские и политические практики, а также готовности содействовать общественным движениям. Основными источниками гражданского активизма в современной России являются социально продвинутые, успешные и мобильные группы. При этом установлена прямая зависимость между гражданской активностью и характером жизненного целеполагания, ценностными установками, социальным самочувствием граждан [Седова 2014].

В особое направление исследований гражданского и политического участия оформился молодежный активизм. Одни исследователи исходят из того, что если демократические общества хотят развиваться, то им нужны информированные, заинтересованные и активные граждане. Другие критикуют традиционный подход к оценке гражданской активности молодежи, отмечая спонтанный интерес исследователей и политиков к молодежному активизму на протяжении всего XX в. на основании публичной демонстрации «неуправляемой молодежной энергии» [Омельченко 2005].

В целом факторы формирования гражданского активизма понимаются как условия, оказывающие влияние на мотивацию, ценности и установки участия граждан в общественной деятельности. Факторами успешности гражданского 
движения в традиционном активизме выступают политическая и экономическая ситуация, веская причина или серьезный повод для действий, информационная кампания, усилия и ресурсы, моральное достоинство, организационное единство, идентичность и число участников. В цифровой среде успешность активизма обусловливают доступность Интернета и социальных медиа, владение цифровыми навыками и технологиями коммуникаций [George, Leidner 2019].

Технология и использование цифровых медиа изменили способ участия молодежи в активистской деятельности во всем мире [Valenzuela 2013]. Однако некоторые российские исследователи потенциал гражданского интернетактивизма считают переоцененным, не находя заметных различий в уровне активности между пользователями и не пользователями социальных медиа, но признавая способность цифровых коммуникаций посредством «слабых сетей» вовлекать их в общественную и политическую деятельность [Бараш, Петухов, Петухов 2015]. Интернет скорее способен усилить процесс политической консолидации участников движения, мультиплицировать протест, нежели внести решающий вклад в реальный успех гражданского движения по организации общественного давления на власть [Сибирев, Головин, Клебанов 2018].

В современных исследованиях позиция, согласно которой использование Интернета оказывает положительное влияние на политическое участие, находит все больше подтверждений [Пырма 2019]. Платформы цифровых коммуникаций выступают центральными площадками формулирования целей, формирования идентичностей и координации гражданских действий сообществ [Ахременко, Стукал, Петров 2020]. Исследователи на основании дифференциации установок гражданской и политической активности определили характеристики сетевых ролей «идеалистов», «прагматиков» и «традиционалистов» [Бродовская и др. 2019а]. Анализ установок молодежи России на реализацию «Цифрового гражданства» выявил значимые связи между оценками сетевых политических и гражданских практик и ценностными ориентациями [Бродовская и др. 2019б].

Методика исследования. Факторы гражданской активности молодежи выявлены на основе качественного метода социологических исследований. Содержательный фундамент исследования - результаты глубинных интервью, проведенных с 35 молодежными лидерами и активистами гражданских и политических организаций России. Определение иерархии факторов, влияющих на формирование установок и культуры гражданского активизма, осуществлялось на основании разработки факторной операционализации. В основе типологии факторов лежит представление о структурных компонентах политической жизни общества. Гайд глубинного интервью содержал следующие модули:

- мотивацию вовлечения в гражданскую активность;

- особенности консолидации внутри организации;

- модель взаимодействия с властными структурами;

- модель взаимодействия со структурами гражданского общества;

- практику привлечения сторонников в офлайн- и онлайн-форматах;

- практику формирования у молодежи культуры и установок гражданской активности;

- соотношение личных жизненных и гражданских ценностей.

Анализ исследования. Рассмотрение стенограмм глубинных интервью выявило специфику аффективной, когнитивной и поведенческой составляющей факторов участия российской молодежи в общественных и политических объединениях в зависимости от роли в организации (движении) и типа объединения по сфере деятельности. Наиболее явно указанные отличия прояви- 
лись в фрагментах интервью, связанных с мотивацией участия респондентов в гражданской и/или политической активности, а также их жизненными ценностями. Лидеры и представители актива объединений демонстрируют особую значимость идейной и ценностной основы, составляющей идеологию и задающей социальные цели.

«Подтолкнула меня какая-то несправедливость, почитал в Интернете про разные политические течения, направления и понял, что коммунистические идеи мне более близки и, собственно, решил» (лидер, парень, 25 лет, Ленинский комсомол) ${ }^{1}$.

«Я хотел попасть в такого рода организацию и заниматься такими задачами, пусть я не езжу сам, не спасаю редких животных, не участвую в экспедициях, исследованиях, не штудирую научные труды, я все равно часть команды, вношу эту коммуникационную лепту по взаимодействию с аудиторией и чувствую себя причастным к сохранению планеты и природы, поэтому это дает мне отдушину, я не могу воспринимать полноценно как работу, для меня это как волонтерство» (лидер, парень, 29 лет, $W W F$ России).

«В жизни сталкивалась с огромным количеством несправедливости, в 1011 классе я для себя свои убеждения, которые были внутри меня, сформулировала в феминизм» (лидер, девушка, 20 лет, СоцФемАльтернатива).

Мотивация участия рядовых членов политических и общественных объединений характеризуется зачастую направленностью на референтную личность лидера организации (движения). Таким образом, вовлечение данного типа участников общественных движений происходит с помощью механизмов подражания, проекции и присоединения. Довольно явно можно проследить размытую, неконкретную и нечеткую артикуляцию мотивов участия у рядовых членов.

«Если говорить обобщенно, то я вышел на личность Дугина, заинтересовался его трудами всем тем, что он создал, о чем писал, о чем говорил, включая и его лекции, заканчивая общественно-политическим движением» (активист, парень, 27 лет, Евразийский союз молодежи).

«Подтолкнула к участию, скорее всего, моя подруга. Когда я пришла в институт все ребята активно занимались волонтерской деятельностью и общественной работой, давайте помогать миру, условно. Я посмотрела, подумала, что надо попробовать, и с тех пор я занимаюсь волонтерской деятельностью» (активист, 19 лет, девушка, Центр помощи женщинам, пострадавшим от домашнего насилия «АННА»).

«Я решил пойти в организацию из-за знакомых, но и за того, что “Молодежное Яблоко” в России является одной из немногих леволиберальных молодежных организаций на деле, но де-факто никакой идеологии в ней нет, что тоже огромнейший плюс» (активист, парень, 19 лет, «Молодежное Яблоко»).

«Сама идея нести в массу информацию о Великой Отечественной войне» (активист, девушка, 20 лет, «Волонтеры Победы»).

Достаточно тесно с мотивацией участия в общественных объединениях связано понимание российской молодежью своих жизненных ценностей. В ответах лидеров доминирует идейная мотивация участия в работе политических и общественных организаций. Чаще всего прослеживается ориентация на ценности общественной справедливости, всеобщего благосостояния, социального равенства, оказания помощи нуждающимся.

«Стремлюсь скорее к справедливости, чтобы она была в нашем обществе,

1 Здесь и далее сохранена орфография и пунктуация источника. 
чтобы богатые не были слишком богатыми, а все остальные бедными» (лидер, парень, 25 лет, Ленинский комсомол).

«Моя главная цель - это помочь всем людям. Я хочу получить образование и скорее всего я буду развиваться в научной сфере: магистратура, аспирантура и именно своей научной деятельностью я буду помогать людям» (лидер, девушка, 20 лет, СоцФемАльтернатива).

По вполне понятным обстоятельствам наблюдаются существенные отличия в жизненных приоритетах у сторонников проправительственных и оппозиционных партий. Доминантой у участников оппозиционных партий является несогласие с курсом нынешней власти. Еще одним приоритетом у представителей оппозиционных объединений являются прагматичные цели участия в деятельности данных организаций.

«Я стремлюсь к тому, чтобы изменить свою страну, мне нравится эта страна, но мне не нравится это государство» (активист, парень, 19 лет, «Молодежное Яблоко»).

«Целей очень много, как у всех у нас. Есть краткосрочные и долгосрочные. Глобальные через 5 лет вижу себя в Думе, через 10 в Правительстве, так как мне будет 30 лет вижу себя самым молодым Губернатором. А партия, конечно, помогает в 18 лет я в первый раз избирался в муниципальную думу в городе Москва» (лидер, парень, 20 лет, Молодежная организация ЛДПР).

«Может быть, научат что-то организовывать. Английский подтянуть на международных мероприятиях. Хочешь не хочешь, придется говорить. Это большое развитие. Чернила в печать заправить в административной работе. Такие навыки, которые нужны в жизни» (активист, 19 лет, девушка, Центр городских волонтеров СПб).

Ответы на вопросы о модели консолидации внутри организации выявили запрос на демократический стиль взаимодействия между лидером и рядовыми членами объединения. Особое значение для информантов имеет открытость лидера критике, его личностная доступность. Примечательно, что фактически респонденты затруднились с адекватным ответом на данный вопрос, подменили понятие типа консолидации типом координации объединения.

«У нас организация не начальников, у нас организация товарищей в первую очередь. Поэтому любой рядовой член организации может позвонить руководителю, Первому Секретарю Центрального комитета и задать ему интересующий вопрос. В этом у нас проблем нет» (лидер, парень, 25 лет, Ленинский комсомол).

«Каждый член организации имеет достаточно прав, чтобы выступать против мнения лидера и даже изменить мнение организации. Нас объединяют либерально-демократические ценности, опять же плюрализм, который я ставлю во главу угла “Молодежного Яблока” (активист, парень, 19 лет, «Молодежное Яблоко»).

«Объединяющим фактором являются общие идеалы и лидерство, то есть к идеалам я бы отнес председателя партии, на него нужно ссылаться» (лидер, парень, 20 лет, Молодежная организация ЛДПР).

При взаимодействии с властью общественные объединения придерживаются интерактивной стратегии. Как правило, данное взаимодействие носит бессистемный, разовый, ситуационный характер. У оппозиционных образований чаще всего такая стратегия сводится к деконструктивной и не адекватной поставленным целям модели конструирования в социальных медиа критически ориентированных дискурсивных практик, выражения несогласия с решениями власти.

«Взаимодействие происходит точечно от ситуации к ситуации. В основном этим занимается руководство КПРФ... Обычно мы, конечно, создаем крити- 
ческий дискурс, все-таки мы оппозиционная организация» (лидер, парень, 25 лет, Ленинский комсомол).

«Нет общих точек соприкосновения, наше государство капиталистическое, отвратительно капиталистическое, худший вид капитализма, который может существовать. Наша организация идет врозь с возможностью финансироваться со стороны государства, так как оно авторитарное» (лидер, девушка, 20 лет, СоцФемАльтернатива).

«Про какое-то сотрудничество сложно сказать. Есть определенное взаимодействие, так как мы тесно соприкасаемся с партийными делами. С органами исполнительной власти соприкасаемся, все больше молодых ребят становятся депутатами муниципальными и городскими, законодательного собрания» (лидер, парень, 29 года, Ленинский комсомол).

Культуре некоторых общественных и политических организаций свойственно понимание взаимодействия с властью как преимущественно протестной активности, представление о ней как о единственно продуктивной форме достижения поставленных целей. Отвечая на вопрос о форматах такого взаимодействия, представители оппозиционных общественных объединений концентрировались на опыте и возможностях развития неконвенциональной активности, включая организацию пикетов, протестных акций и митингов.

«Массовые акции протеста нужны, чтобы влиять на людей, которые принимают политические решения. Так разговор про закон о домашнем насилии идет благодаря как раз повышенному вниманию в этой теме, благодаря пикетам» (активист, девушка, 19 лет, Центр помощи женщинам, пострадавшим от домашнего насилия «АННА»).

«Мы организовывали митинги и пикеты, когда был проект “Честное голосование" 〈... Стране нужны забастовки. Европа бастует и добивается своего, а у нас как-то все с этим плохо» (активист, девушка, 24 года, штаб Навального).

Относительно коммуникаций с другими институтами гражданского общества получены ответы, отраженные в признании необходимости сотрудничать с близкими по целям организациями. Вместе с тем ни лидеры, ни активисты не указали на регулярные форматы данных интеракций.

«Мы стараемся поддерживать хорошие отношения с близкими к нам по ценностям и идеалам организациями, например, с партией “Яблоко”, с Либертарианской партией России, с ПАРНАСом, с местными активистскими группами в Петербурге или других регионах» (лидер, девушка, 24 года, «Весна»).

«Мы взаимодействуем с различными объединениями, если у нас сходятся цели и задачи какие-то, стратегические цели у нас сходится не могут, а тактические вопросы мы можем решать, какие-то мероприятия проводить» (лидер, парень, 25 лет, Ленинский комсомол).

Изучение методов масштабирования целевых аудиторий, применяемых общественными объединениями, заслуживает особого внимания. В целом можно констатировать ситуационную, несистемную работу с таргетными группами, не основанную на применении ни календарного плана, ни программы цифрового рекрутинга, ни тем более концепции социально-медийного сопровождения деятельности объединения.

«У нас в первую очередь - это точечная работа. Нельзя всех подряд принимать, так как это бесполезно глупо и неэффективно, потом эти люди пропадают, их исключать надо» (лидер, парень, 25 лет, Ленинский комсомол).

«Сейчас у нас нет конкретной цели набрать множество сторонников. Мы каждый день стараемся публиковать посты в разные социальные сети» (лидер, девушка, 20 лет, СоцФемАльтернатива). 
«У нас есть определенная специфика отбора участников и привлечения их в организацию, так как мы организация, которая имеет серьезную идеологическую платформу. Мы не можем набирать для числа людей, так организация давно бы перевалила за 50 тыс., если бы брали всех, кого не попадя» (лидер, 29 лет, парень, Ленинский комсомол).

«На самом деле, работа наших экспертов она в основном кабинетная. Они исследуют тонны бумаг, например, выходит какой-то новый законопроект, они его исследуют вдоль и поперек и понимают то вот это пойдет на пользу нашим задачам по спасению конкретного вида, а вот это поставит его под угрозу и готовят предложения по поправкам» (лидер, парень, 30 лет, $W W F$ России).

Все перечисленное выше свидетельствует об отсутствии четкого представления о стратегии социально-медийного сопровождения деятельности объединения, об отсутствии внимания к этому направлению как отдельной важной и значимой работе, которая должна быть подкреплена профильными специалистами.

«У нас нет сайтов рекрутирования. У нас живые люди все по-настоящему. Встретили нас на улице ребята: "О красиво, круто, что делаете? А с вами можно?” Обменялись контактами, пригласили. Возможно есть набор в ВК или в Инстаграме» (активист, парень, 21 год, ОНФ).

«В основном пассивный поиск идет. Мы можем на разных площадках и презентовать нашу организацию и уже конкретно целенаправленно агитировать за вступление заинтересованной молодежи, но все-таки у нас основная работа состоит в том, что мы показываем, что мы делаем. Любой человек, для которого наши цели и задачи идентичны, может вступить» (лидер, парень, 24 года, Молодая гвардия).

«У нас основной канал привлечения сторонников - это волонтеры, которые приезжают в фонд и после прохождения программ становятся чуть ли не амбассадорами идей фонда. Они очень сильно через свое сарафанное радио продвигают идеи фонда, привлекают новых волонтеров, спонсоров. Кто-то рассказывает в медучреждениях о таких программах» (лидер, девушка, 29 лет, благотворительный фонд «Шередарь»).

«У нас есть цель привлечь волонтеров на постоянной основе, еще привлечь авто помощь, спонсоров, фотографа, журналистов. В “Инстаграм” ищем блогеров, которые могут помочь и раскрутить проблему, если нам нужна авто помощь, как недавно из Чебоксар в Москву нужно было перевезти животное» (лидер, девушка, 30 год, Фонд защиты животных «УМКА»).

«Мы рассылаем призыв людям в групповые чаты, которые остались после мероприятий. Люди говорят: “Мы хотим еще!” (активист, 19 лет, девушка, Центр городских волонтеров СПб).

Таким образом, обнаруживается отсутствие осознания у представителей молодежного общественного сектора важности задачи поставить социальномедийную работу на профессиональные рельсы; на уровне общей интуиции и здравого смысла существует убежденность в необходимости осуществления этой активности.

Анализируя ответы респондентов об одной из ключевых задач общественных объединений - методах формирования гражданских установок молодежи, отметим преобладание традиционных форматов ценностного воздействия на молодежную аудиторию, имеющих низкую продуктивность и низкий потенциал вовлечения широких слоев молодого поколения в гражданскую активность.

«В принципе мы проводим культурные мероприятия и в МХАТе, и в офисе Евразийского движения, и с иностранными гостями, и с патриотами, и с узким кругом. Коммуникации с обществом идут по ряду направлений, если мы берем 
культурную часть, то задействуем и МХАТ, и круглые столы, и Интернет, и многие люди пишут, многие потом обращаются, потом пропадают у них порыв проходит, кто-то остается» (активист, парень, 30 лет, Евразийский союз молодежи).

«Пикеты, массовые акции протеста мы пока не организуем, но при этом принимаем участие в разнообразных эфирах, подкастах, которые тоже имеют своей целью просвещение и попытку заявить о себе. Так вообще у нас в принципе в России все строится вокруг пикетов и разнообразных митингов» (активист, парень, 19 лет, «Молодежное Яблоко»).

«Традиционно мы выходим Первого мая, 23 февраля, отмечаем день армии. Ежегодно это 3 и 4 октября - день расстрела Белого дома в 93-м году. А так мы проводим всякое разное, на разные темы. Вот сейчас у нас прошли одиночные пикеты по теме 3-дневного голосования, которое Госдума одобрила. До этого мы проводили акции протеста против принятия поправок в Конституцию» (лидер, парень, 25 лет, Ленинский комсомол).

«Цельной программы по формированию установок гражданской активности нет, но организуются точечные акции в привязке к событиям. Мы проводили недавно дебаты с гражданским обществом либертарианцев - у них появилась феминистская фракция, которая занимается положением женщин в капитализме. В основном у нас есть девушки, которые участвуют в наших чатах от разных организаций» (лидер, девушка, 20 лет, СоцФемАльтернатива).

«"Молодежное Яблоко” занимается просветительской деятельностью в плане политической грамотности. Мы проводим разнообразные лекции, связанные как с историей, так и с современной действительностью. Приглашаем различных спикеров как из различных правозащитных организаций, так и из основного “Яблока” (активист, парень, 19 лет, «Молодежное Яблоко»).

«Наша цель помочь и вдохновить на активные действия и решительные шаги, необязателен формат окультуривания, но необходимо чтобы человек имел свое мнение и свою позицию, умел регулировать свое поведение и потребление» (активист, 27 лет, девушка, «ЭКА! Зеленое движение России»).

«Сейчас политическая позиция стала чем-то личным и стараюсь не принимать участие в политических штуках. Один раз было мероприятие, связанное с поправками в Конституцию. Мы стояли и рассказывали о поправках, не призывая голосовать» (активист, 17 лет, девушка, Мосволонтер).

В ряде случаев респонденты, представляющие «молодежные крылья» политических партий, признавали формальность и имитационность деятельности. В партиях молодежи часто отводятся роли либо массовки на различных акциях, либо волонтеров для распространения агитационных материалов и атрибутики. Молодежь в большинстве случаев исключена из процесса принятия партийных решений, что не способствует ее вовлечению в активную политическую деятельность.

Выводы исследования. Резюмируя результаты анализа глубинных интервью лидеров и активистов общественных объединений, перечислим основные выводы:

1) мотивация к участию в гражданской и политической активности у лидеров и активистов в большей степени идейная, тогда как у простых сторонников - подражательная, основанная на авторитете руководителя организации или движения;

2) лидерам и активистам в большей мере присущи макросоциальные жизненные приоритеты (достижение целей социальной справедливости и всеобщего блага), рядовым членам - прагматические (совершенствование SOFT skills, партийная карьера и возможность достижения позиций в органах власти); 
3) доминирующей установкой оппозиционных объединений является ориентация на протестную активность как наиболее эффективную форму взаимодействия с органами власти;

4) общественные объединения фактически не реализуют социально-медийные форматы масштабирования целевой аудитории, не ведут систематическую работу по привлечению сторонников в социальных медиа;

5) факторами мотивации к участию в форматах гражданского активизма у лидеров и активистов выступают идейная близость, возможность социального влияния, тщеславие, целеустремленность и социальное признание;

6) факторами формирования неконвенциональных установок гражданского активизма у лидеров и активистов выступают материальная выгода, пренебрежительное отношение к законам страны, восприятие протестных акций как наиболее эффективного метода привлечения внимания к проблеме/объединению/персоне, прагматичные ценности;

7) факторами формирования конвенциональных установок гражданского активизма у лидеров и активистов выступают уважение к конституции и законам страны, установка на стремление к позитивному взаимодействию с органами власти, положительный опыт совместного с властью решения социальных проблем, макросоциальные ценности справедливости, стабильности, порядочности.

В перспективе исследование гражданского участия видится в разработке системы прогнозирования политической активности на основе метода агентного имитационного моделирования с учетом факторов масштаба, характера, направленности и вовлеченности молодежи в онлайн- и офлайн-практики.

\section{Список литературы}

Ахременко А.С., Стукал Д.К., Петров А.П. 2020. Сеть или текст? Факторы распространения протеста в социальных медиа: теория и анализ данных. Полис. Политические исследования. № 2. С. 73-91.

Бараш Р.Э., Петухов В.В., Петухов Р.В. 2015. Информационнокоммуникационные факторы формирования новых практик гражданского активизма. - Социологическая наука и социальная практика. № 4(12). С. 99-125.

Бродовская Е.В., Домбровская А.Ю., Пырма Р.В., Азаров А.А. 2019а. Гражданские и политические онлайн-практики в оценках российской молодежи (2018). - Политическая наука. № 2. С. 180-197.

Бродовская Е.В., Домбровская А.Ю., Пырма Р.В., Азаров А.А., Синяков А.В. 2019б. «Цифровая гражданственность» в оценках российской молодежи. Политическая экспертиза: ПОЛИТЭКС. Т. 15. № 3. С. 326-344.

Омельченко Е.Л. 2005. Молодежный активизм в России и глобальные трансформации его смысла. - Журнал исследований социальной политики. № 3(1). C. 59-86.

Пырма Р.В. 2019. Влияние цифровых коммуникаций на политическое участие. - Гуманитарные науки. Вестник Финансового университета. Т. 9. № 4(40). С. 63-69.

Седова Н.Н. 2014. Гражданский активизм в современной России. Социологический журнал. № 2. С. 48-71.

Сибирев В.А., Головин Н.А., Клебанов А.А. 2018. Сетевые сообщества в борьбе вокруг решения передать Исаакиевский собор Русской православной церкви (январь-июнь 2017 года). - Мониторинг общественного мнения: экономические и социальные перемены. № 1. С. 296-317.

Трофимова И.Н. 2014. Гражданский активизм в России: новые реалии. NOTA BENE. № 9. C. 1020-1031. 
George J., Leidner D. 2019. From Clicktivism to Hacktivism: Understanding Digital Activism. - Information and Organization. Vol. 29. Is. 3. 100249.

Valenzuela S. 2013. Unpacking the Use of Social Media for Protest Behavior. The Roles of Information, Opinion Expression, and Activism. -American Behavioral Scientist. Vol. 57. Is. 7. P. 920-942.

PYRMA Roman Vasil'evich, Cand.Sci. (Pol.Sci.), Associate Professor of the Department of Political Science, Faculty of Social Sciences and Mass Communications, Financial University under the Government of the Russian Federation (49 Leningradsky Ave, GSP-3, Moscow, Russia, 125993; pyrma@mail.ru)

\title{
FACTORS THAT FORM THE ATTITUDES AND CIVIL ACTIVISM STRATEGIES AMONG RUSSIA'S YOUTH
}

\begin{abstract}
Based on in-depth interviews with leaders and activists of public and political organizations the article identifies the factors influencing the formation of the values of civic activism of young people. The structure of the study includes consideration of ways of engaging in civic engagement, the characteristics of consolidation within the organization (values, believes, identities, leader's authority, mechanisms of cohesion), interaction with government structures and civil society, and attracting supporters in offline and online environments. In addition, the author shows the factors of the formation of culture and attitudes of civic activity, the ratio of personal life and civic values, and the role of youth in organizations. The motivation for participation in civic and political activity of leaders and activists is dictated by ideological convictions, achievement of social status and recognition. The values of pragmatism, material gain, legal nihilism, and disdainful attitude of certain groups of young people to the laws of the country, the perception of protest actions as the most effective method of drawing attention to the problem, association or person are the personal factors in the formation of unconventional attitudes of civic activism. On the contrary, personal factors in the formation of conventional attitudes of civic activism are formed from respect for the constitution and laws of the country, the desire for positive interaction with the authorities, the development of the practice of jointly solving social problems based on the values of justice, morality and stability. Keywords: civic activism, political participation, protest moods, conventional attitudes, youth
\end{abstract}

